\title{
Sistem Informasi Pengolahan Data Nilai Berbasis Web Pada SMA Al-Husna Curug
}

\author{
Nur Azizah ${ }^{1}$, Belsana Butar Butar ${ }^{2}$, Lupita Sari ${ }^{3}$ \\ Program Studi Sistem Informasi Universitas Raharja ${ }^{1}$, Program Studi Sistem Informasi Universitas \\ Bina Sarana Informatika Jakarta ${ }^{2}$, Program Studi Sistem Informasi Universitas Nusa Mandiri Jakarta ${ }^{3}$ \\ Email: nur.azizah@raharja.info ${ }^{1}$, belsana.bbb@bsi.ac.id ${ }^{2}$,pitaa845@gmail.com ${ }^{3}$
}

\begin{abstract}
Abstrak
Sistem Informasi Akademik Penilaian berbasis web pada SMA Al-Husna Curug ini bertujuan untuk mempermudah guru dan siswa dalam memperoleh informasi akademik dan melakukan penilaian secara online. Sehingga dapat mengurangi kesalahan dalam pencatatan, kurang akuratnya dalam penulisan laporan dan dalam pencarian data yang diperlukan tidak mengalami kesulitan. Selain itu dengan berbsiskan web maka informasi data dapat diakses dengan waktu dan tempat yang tidak ditentukan. Dengan sistem yang telah terkomputerisasi maka waktu yang digunakan jauh lebih efektif dan efisien sehingga guru dan siswa tidak mengalami kesulitan dalam kegiatan akademik. Metode yang digunakan dalam sistem ini adalah metode waterfall. Sistem informasi Pengolahan Data Nilai berbasis web ini dibuat dengan menggunakan beberapa software yaitu Adobe Dreamweaver CS6 sebagai web editor, XAMPP sebagai web server. Dengan menggunakan software-software tersebut pengerjaan web menjadi lebih mudah.
\end{abstract}

Kata Kunci : Akademik, Penilaian, web, waterfall.

\begin{abstract}
Academic information system web-based assesment on SMA Al-Husna Curug aims to facilitate teachears and students in obtaining information and conducting academic assesment online. Reducing errors in the recording, so less, accurate in the writting of the report and in the search for necessary data have no trouble. In adition wit the web-based information data can be accessed with the time and place was not specified.with the computerized system then time spent much more effectively and efficiently so that teachers and students do not have difficulty in academic activities. The methods use in this system is a method of waterfall. Data processing information system web-bassed value is created by using some software i.e. Adobe Dreamweaver CS6 as web editor, XAMPP as a web server. By using the software work the web became easier.
\end{abstract}

Keywords: Academic, assessment, web, waterfall.

\section{PENDAHULUAN}

SMA AL-HUSNA CURUG sebagai salah satu lembaga pendidikan swasta yang menyelenggarakan pendidikan tingkat sekolah menengah atas, dimana dalam mengolah data nilai di sekolah tersebut sebagian besar masih dilakukan secara konvensional. Pengolahan data nilai siswa di SMA AL-HUSNA CURUG yang masih dilakukan secara konvensional yaitu dengan menggunakan Microsoft Excel dan pencatatan menggunakan kertas. Pengolahan data yang masih dilakukan dengan cara tersebut menyebabkan beberapa permasalahan dan kendala, diantaranya nilai ditulis dilemabran buku terlebih dahulu, baru kemudian di input ke aplikasi Microsoft Excel oleh masing- masing guru, selanjutnya nilai di berikan ke wali kelas untuk diolah kembali. Jika buku tersebut hilang atau rusak, dan guru tersebut terlambat dalam menyerahkan nilai ke wali kelas tentunya dapat mengakibatkan keterlambatan dalam pembuatan daftar nilai dan penyerahan nilai ke siswa. Masalah lainnya, sering sekali guru kesulitan dalam menghitung dan mengolah data siswa, pencarian dokumen-dokumen atau berkas siswa juga membutuhkan waktu yang cukup lama, sering ditemukan data yang tidak konsisten dan menyebabkan data-data yang ada mudah hilang maupun rusak. Hal ini rentan mengganggu proses akhir dari belajar mengajar. Oleh karena itu diperlukan sebuah solusi atas permasalahan yang ada dengan membuat sebuah aplikasi sistem informasi yang mampu mendukung pengolahan data nilai siswa dengan cepat. Sehingga penelitian ini diharapkan memiliki peranan untuk memperbaiki kinerja sistem pengolahan data nilai akademik SMA AL-HUSNA CURUG. 


\section{B. Landasan Teori}

a. Sistem

Secara sederhana sistem merupaka suatu kumpulan elemen data atau unsur, juga komponen atau variabel-variabel yang sudah terorganisasir, yang dapt berinteraksi, saling tergantung satu sama lain dan terpadu dan memiliki tujuan.[9]

b. Informasi Informasi dapat dijelaskan sebagai data yang telah diklasifikasikan atau diinterpretasikan untuk digunakan daam proses setiap pengambilan keputusan oleh pihak-pihak terkait. [10]

c. Entity Relationship Diagram

Suatu pemodelan database yang menggunakan diagram relasi antar entitas sehingga dapat mengurangi atau menghilangkan redundancy. [6]

d. Internet

Internet sebagai sebuah jaringan yang menghubungkan antar komputer-komputer secara global sehingga tidak terdapat batas wilayah atau jarak, yang dapat dengan menggunakan standar Internet Protocol Suite (TCP/IP) saat proses tukar menukar data missal user A dengan user B.[13]

e. Web

Web mengacu kepada kumpulan dari beberapa objek, maupun dokumen, yang besar dan saling berinterakasi, dan tersedia untuk semua orang dengan mengakses Internet. [11]

f. PHP

PHP merupakan sebuah language programming yang digunakan untuk membangun sebuah aplikasi salah satunya berbasis web missal website, blog atau aplikasi web lainnya.[5]

g. JQuery

JQuerya yang merupakan singkatan dari Javascript Library yang merupakan kumpulan kode tunggal Javascript siap pakai, sehingga mempermudah dan mempercepat dalam pembuatan kode Javascript". [12]

h. Javascript

Javascript dapat dikatakan sebagai bahasa yang memiliki fungsi membuat script program yang dapat dikenal serta dieksekusi oleh web server yang memiliki tujuan untuk menjadikan halaman web lebih mudah digunakan dan dipahami. [7]

i. $\mathrm{MySQL}$

MySQL sebagai salah satu tool yang digunakan untukmengolah database (basis data) yang bersifat open source atau tidak berbayar yang dikembangkan oleh komunitas bernama MySQL AB yang tujuan membantu pengguna menyimpan data dalam bentuk tabel. [3]

j. Web Server

Web server yang merupakan perangkat lunak yang memiliki fungsi menerima permintaan (request) berupa halaman web yang berbentuk HTML. [4]

k. Domain

Domain merupakan nama pengganti dari sebuah IP address yang menuju pada server yang dituju serta diwakili oleh adanya website. [1]

1. Hosting

Hosting dapat didefinisikan sebagai suatu bentuk layanan penyewaan lokasi penyimpanan file atau berkas yang berbentuk jaringan dalam hal ini internet. [2]

m. UML ( Unified Modeling Language)

UML (Unified Modeling Language) merupakan salah satu standar dalam mendesign sebuh system baik system berjalan maupun system usulan yang mengarah ke pemrograman berorientasi objek. [8]

C. Identifikasi Masalah

Dari hasil analisa pada sistem informasi akademik yang berjalan di SMA AL-HUSNA Curug, diindetifikasikan permasalahan yaitu:

a. Pembuatan laporan yang masih menggunakan Microsoft Excel.

b. Proses pengolahan nilai yang memakan waktu yang lama dan sering menghadapi kendala pada saat memproses nilai siswa.

c. Kesulitan dalam melakukan pencarian data yang diperlukan mengenai data nilai siswa. 
D. Tujuan Penelitian

Tujuan dari penelitian ini adalah:

a. Merancang sistem pengolahan data nilai pada SMA Al-Husna Curug sehingga menghasilkan informasi yang cepat, tepat dan akurat

b. Mempermudah guru memproses atau mengolah nilai siswa

c. Guru dapat dengan mudah mencari nilai siswa

d. Membuat sistem pengolahan nilai siswa berbasis web yang lebih efektif dan efisien.

\section{METODE PENELITIAN}

Penulis melakukan riset untuk mendapatkan data atau informasi yang akurat mengenai sistem berjalan untuk dianalisa agar penulis sendiri dapat mengetahui kelemahan dan kekurangan yang terdapat pada sistem yang akan dibuat. Dan model pengembangan perangkat lunak yang digunakan pada tulisan ini merupakan salah satu model dari SDLC (System Development Life Cycle) yaitu model waterfall yang sering disebut juga model sequential linear. Dimana model ini menyediakan pendekatan alur hidup perangkat lunak secara terurut dimulai dari analisis, desain, pengkodean, pengujian dan tahap pendukung. Menurut Rosa dan Shalahuddin [8], model waterfall yaitu:

a. Analisis Kebutuhan Perangkat Lunak

Proses pengumpulan kebutuhan dilakukan secara intensif untuk menspesifikasikan kebutuhan perangkat lunak agar dapat dipahami perangkat lunak seperti apa yang dibutuhkan oleh user.

b. Desain

Proses desain perangkat lunak, berfokus pada desain pembuatan program perangkat lunak termasuk struktur data, arsitektur perangkat lunak, representasi antarmuka, dan prosedur pengodean. Tahap ini mentranslasi kebutuhan perangkat lunak dari tahap analisis kebutuhan ke representasi desain agar dapat diimplementasikan menjadi program pada tahap selanjutnya.

c. Pembuatan Kode Program

Desain harus ditranslasikan ke dalam program perangkat lunak. Hasil dari tahap ini adalah program komputer sesuai dengan desain yang telah dibuat pada tahap desain.

d. Pengujian

Pengujian fokus pada perangkat lunak secara dari segi lojik dan fungsional dan memastikan bahwa semua bagian sudah diuji. Hal ini dilakukan untuk meminimalisirkan kesalahan (error) dan memastikan keluaran yang dihasilkan sesuai dengan yang diinginkan.

e. Pendukung (support) atau pemeliharaan (maintenance)

Tidak menutup kemungkinan suatu perangkat lunak mengalami perubahan keika sudah dikirimkan ke user. Perubahan bisa terjadi karena adanya kesalahan yang muncul dan tidak terdeteksi saat pengujian dan perangkat lunak harus beradaptasi dengan lingkungan baru. Tahap pendukung atau pemeliharaan dapat mengulangi proses pengembangan mulai dari analisis spesifikasi untuk perubahan perangkat lunak yang sudah ada, tapi tidak untuk membuat perangkat lunak baru.

\section{HASIL DAN PEMBAHASAN}

Dalam proses pengolahan nilai dan absensi siswa, masing masing guru untuk setiap mata pelajaran akan merekap semua nilai (nilai tugas, UTS dan UAS) juga merekap absensi dari setiap kelas yang mereka ajar, kemudian memberikannya kepada wali kelas. Setelah itu rekap nilai dan absensi akan dicatat kedalam buku ledger. Apabila daftar nilai dan absensi sudah lengkap, maka akan disalin kedalam buku raport dan akan disahkan oleh kepala sekolah. Buku Raport yang telah disahkan akan dikembalikan kepada wali kelas untuk kemudian diberikan kepada siswa.

\section{a. Activity Diagram Sistem Berjalan}

Activity Diagram Sistem Berjalan pada penilitian ini adalah : 


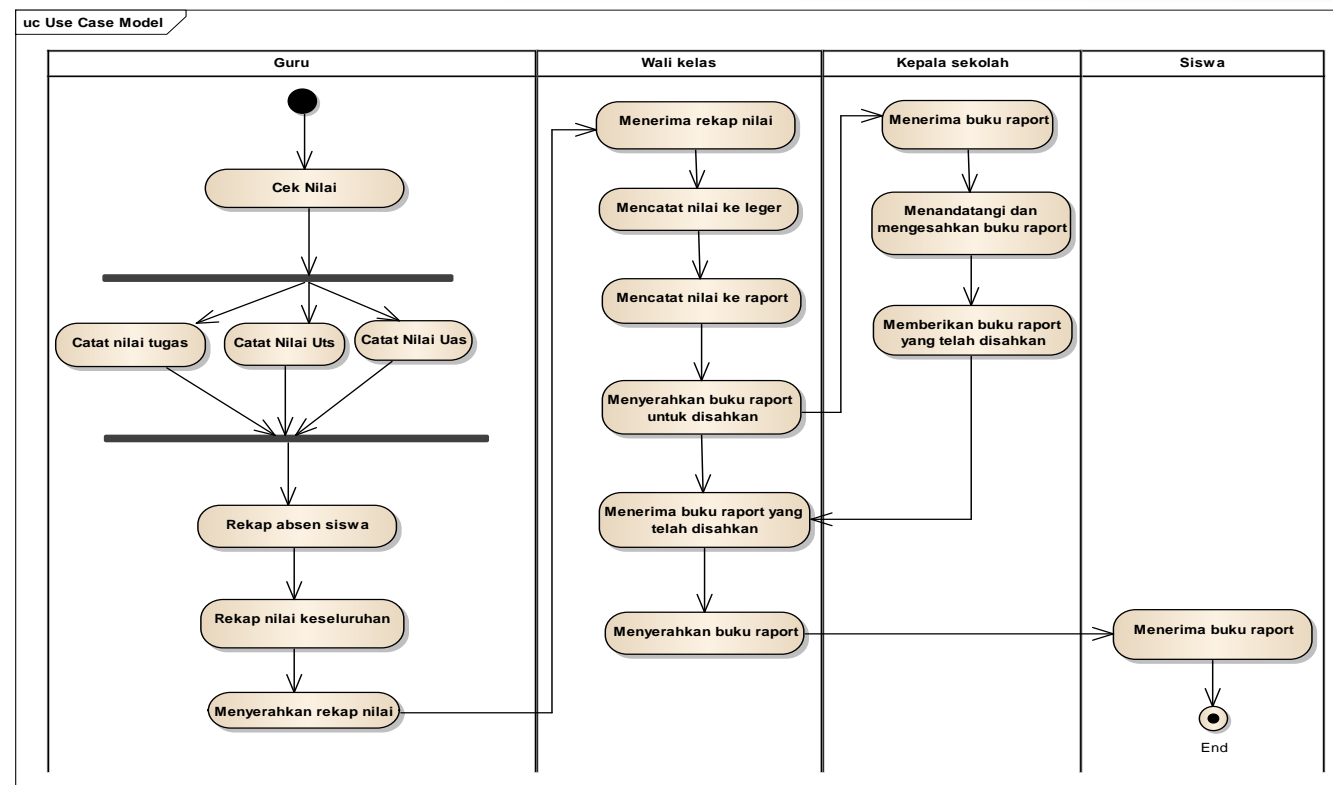

Gambar 1. Activity Diagram Berjalan Pengolahan Nilai Siswa

\section{b. Analisis Kebutuhan dari Sistem}

Sistem informasi Akademik pada SMA Al-Husna Curug dibuat agar memudahkan siswa dan guru dalam mengakses informasi mengenai kegiatan akademik yang ada disekolah dimana mereka tidak harus bertemu dan bertatap muka untuk memperoleh informasi akademik tersebut.

Halaman User:

A.1 Siswa dapat login ke ruang siswa.

A.2 Siswa dapat melihat jadwal mata pelajaran.

A.3 Siswa dapat mencetak jadwal pelajaran.

A.4 Siswa dapat melihat nilai.

A.5 Siswa dapat mencetak nilai

A.6 Guru dapat login ke ruang guru.

A.7 Guru dapat melihat jadwal mengajar.

A.8 Guru dapat mencetak jadwal mengajar.

A.9 Guru dapat menginput nilai siswa.

A.10 Guru dapat melihat nilai siswa.

Halaman Admin:

B1. Admin dapat mengelola data siswa.

B2. Admin dapat mengelola data guru.

B3. Admin dapat menegelola data jadwal pelajaran.

\section{c. Use Case Diagram}

Use case Diagram sistem Pengolahan Data Nilai

1. Halaman Guru

Berikut Use case diagram untuk halaman guru: 


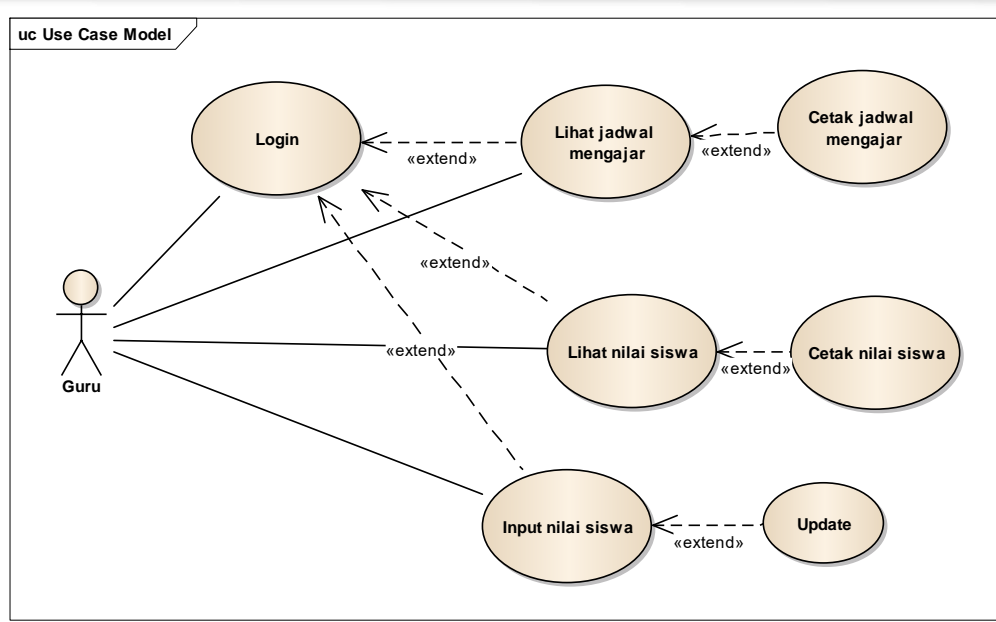

Gambar 2. Use Case Diagram Halaman Guru

\section{Halaman Siswa}

Dibawah ini diagram use case halaman siswa:

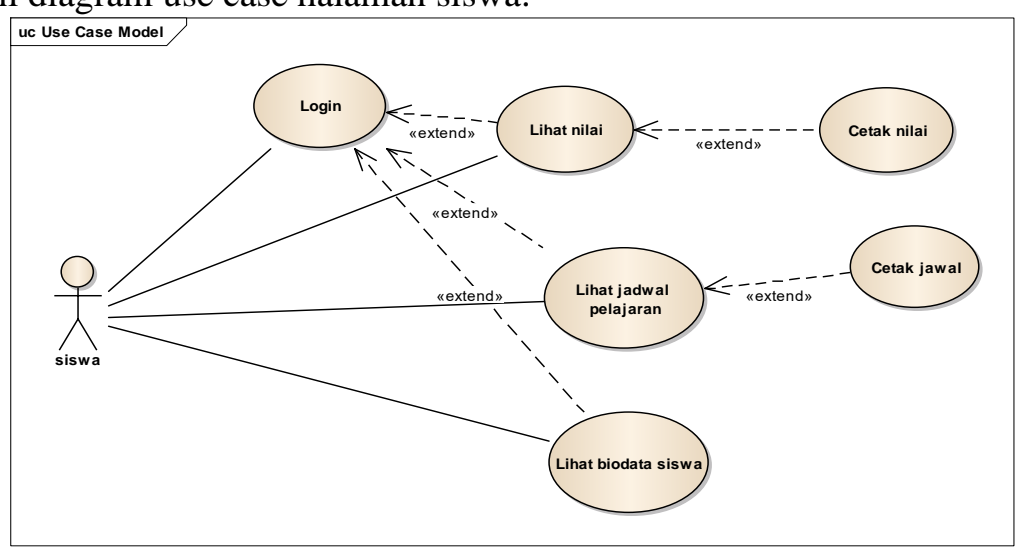

Gambar 3. Use Case Diagram Halaman Siswa

3. Use Case Diagram Halaman admin

Berikut use case diagram halaman admin:

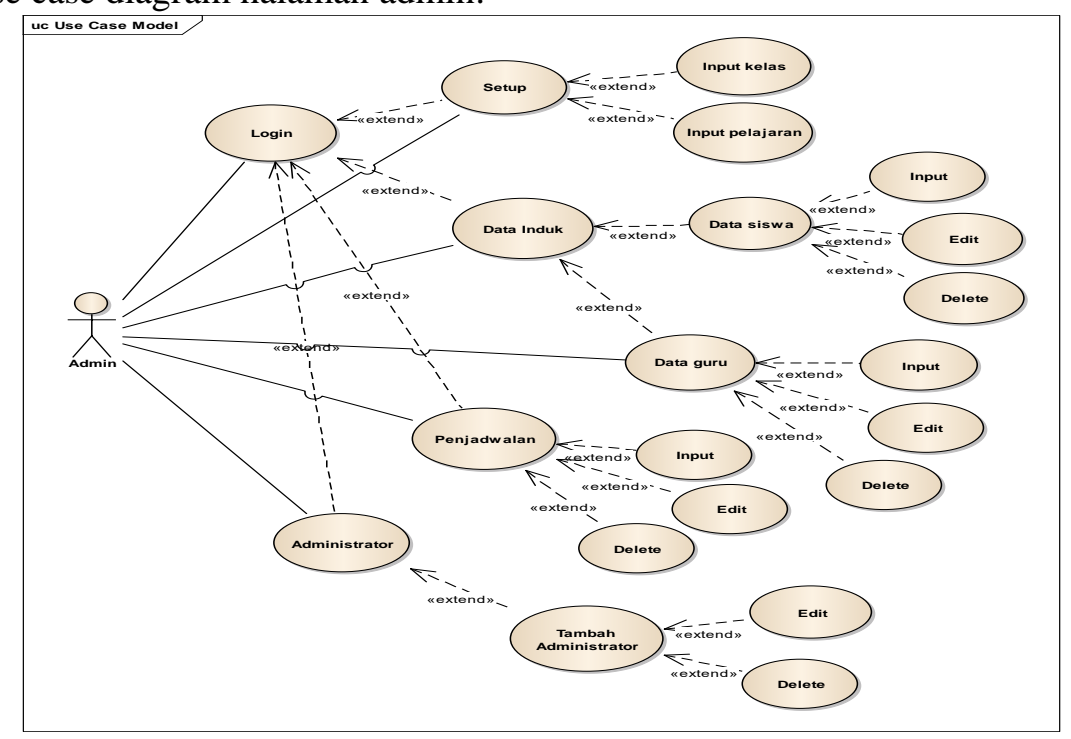

Gambar 4. Use case Diagram Halaman Admin 


\section{d. Activity Diagram}

Dibawah ini diagram use case untuk activity diagram system usulan, yaitu:

1. Activity Diagram Pegolahan Data jadwal pelajaran

Berikut activity diagram untuk mengolah jadwal pelajaran:

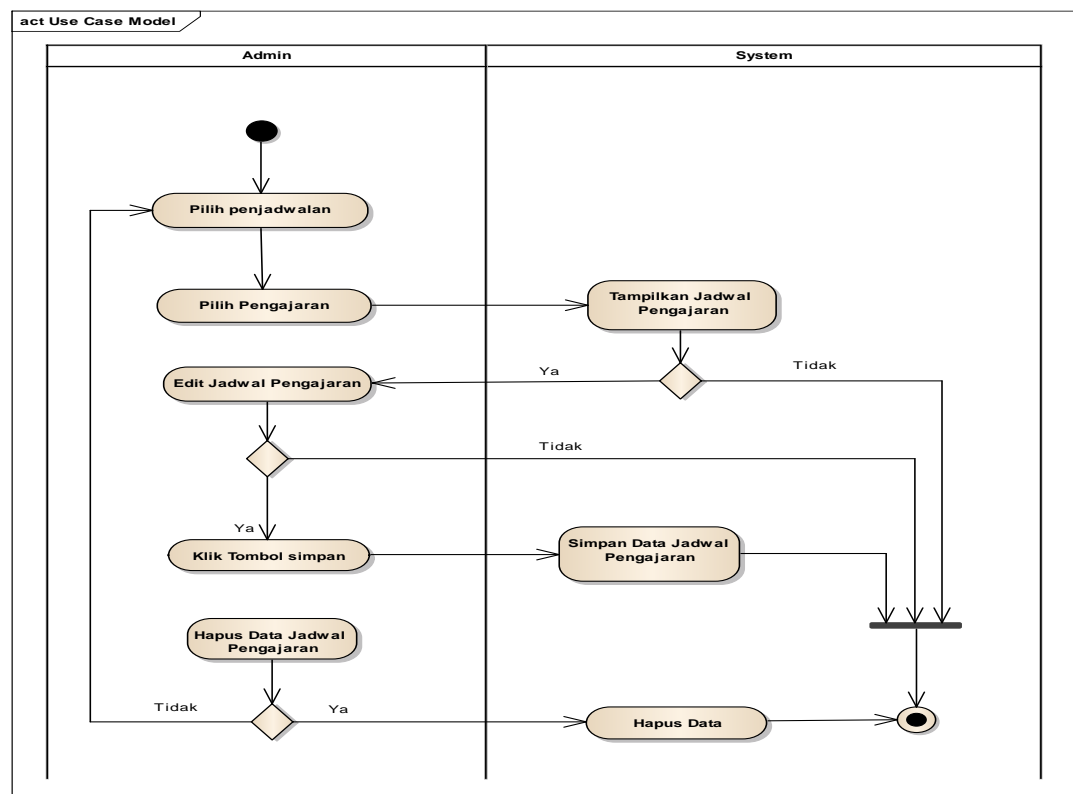

\section{Gambar 5. Activity Diagram Pengolahan data pelajaran}

\section{Activity Diagram Input Nilai Siswa}

Berikut activity diagram untuk mengolah jadwal pelajaran:

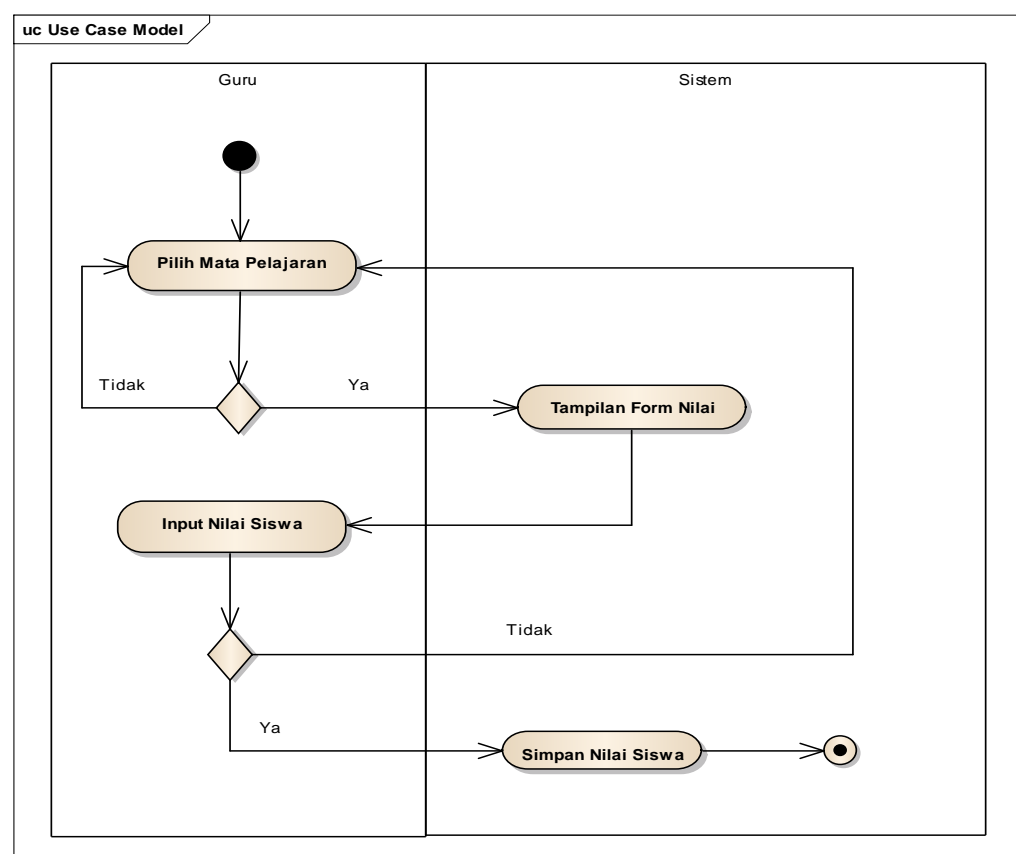

\section{Gambar 6. Activity Diagram Input Nilai}

\section{e. Component Diagram}

Untuk mengolah atau memproses data diperlukan perangkat lunak yaitu: 


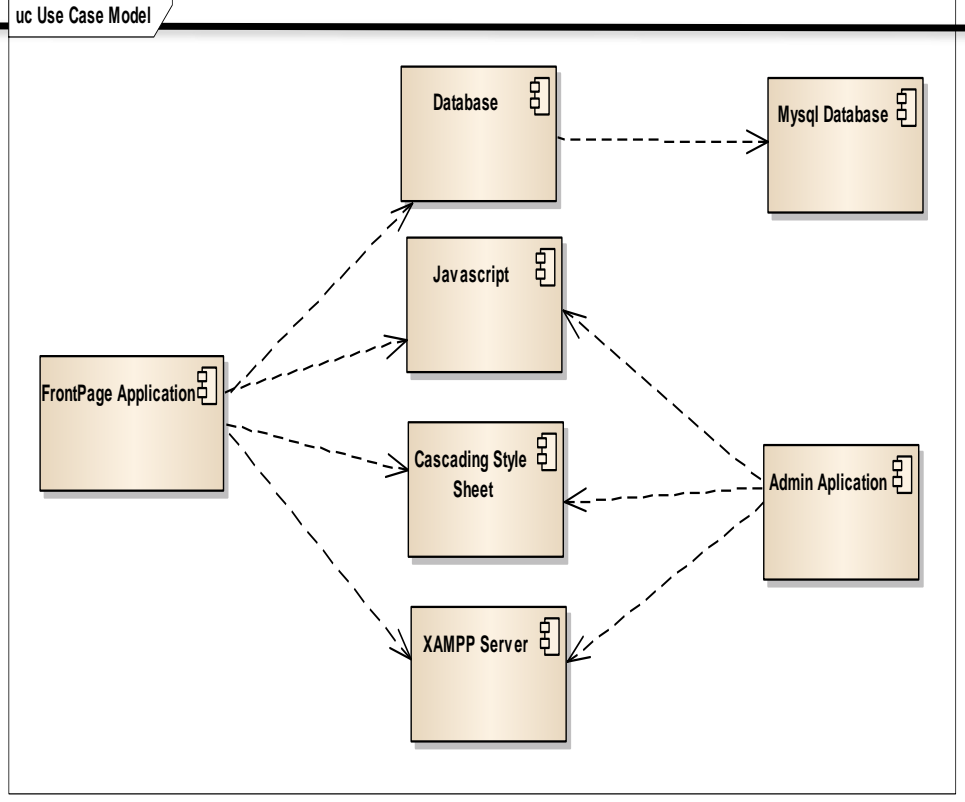

Gambar 7. Component Diagram

\section{f. Deployment Diagram}

Pemanfaatan aplikasi dapat menggunakan hardware yaitu:

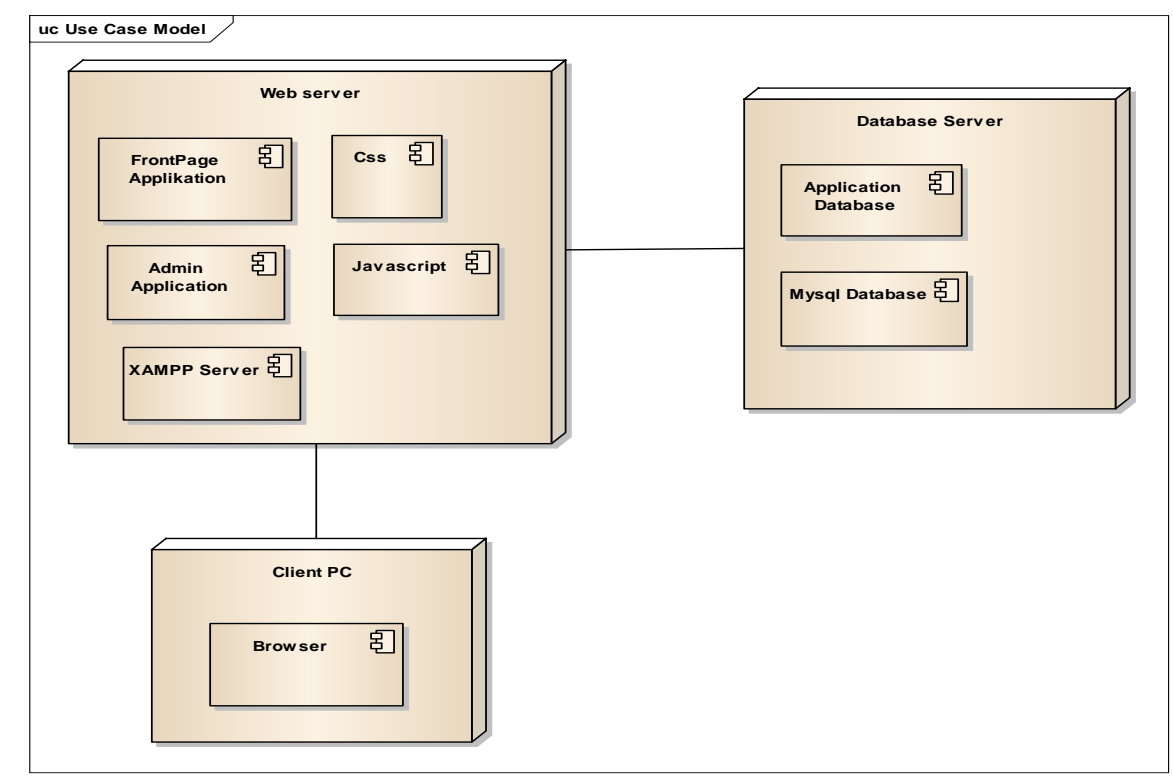

Gambar 8. Deployment Diagram

\section{g. Desain Database}

Data perlu disimpan dalam sebuah database, dan field serta relasi yang dibutuhkan digambarkan dengan menggunakan entity relatioship diagram, yaitu: 


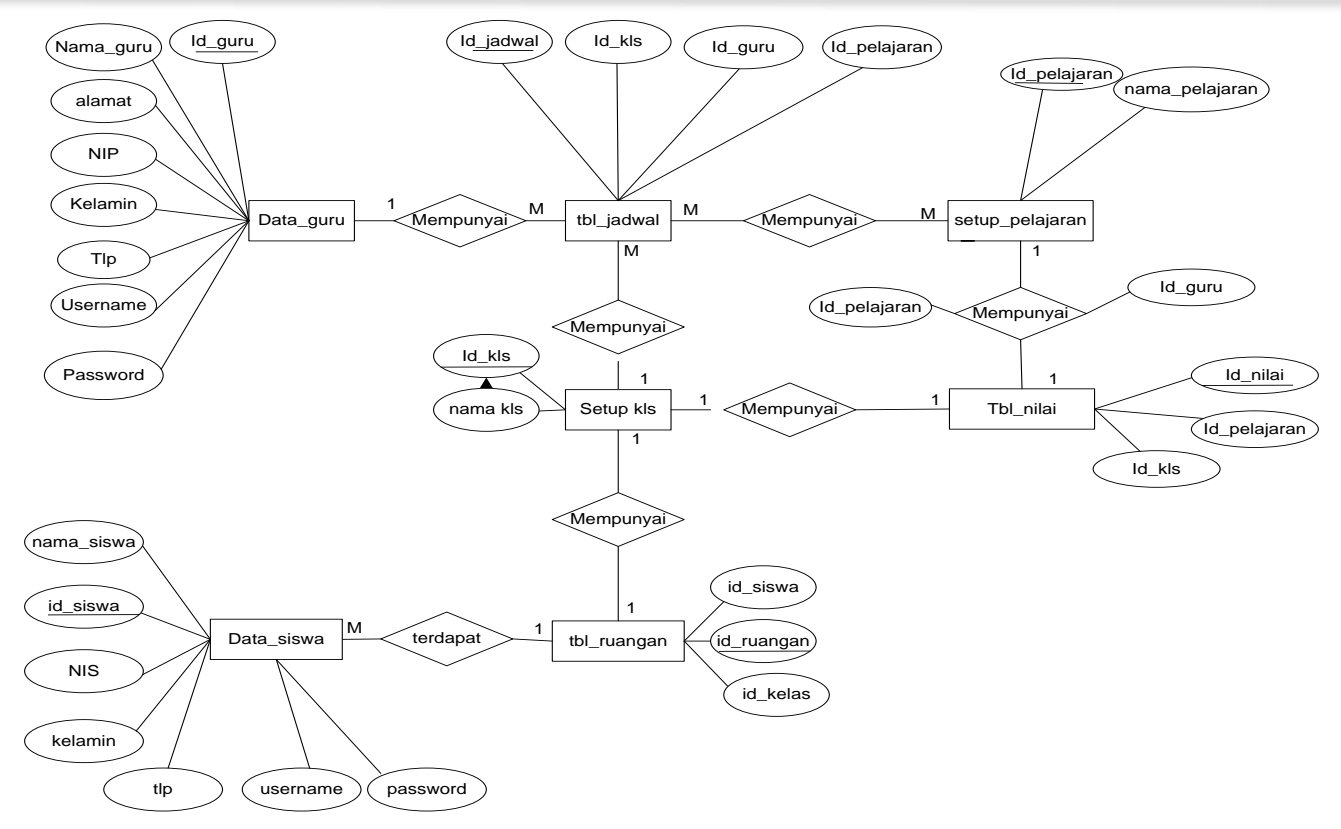

Gambar 9. Entity Relationship Diagram (ERD)

h. Tampilan Program

1. Tampilan Login

Halaman login sebagai berikut:

2. Tampilan home User

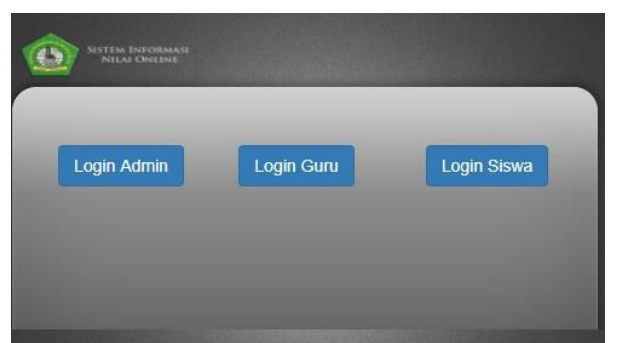

Gambar 10. Tampilan input nilai

Halaman home user sebagai berikut:

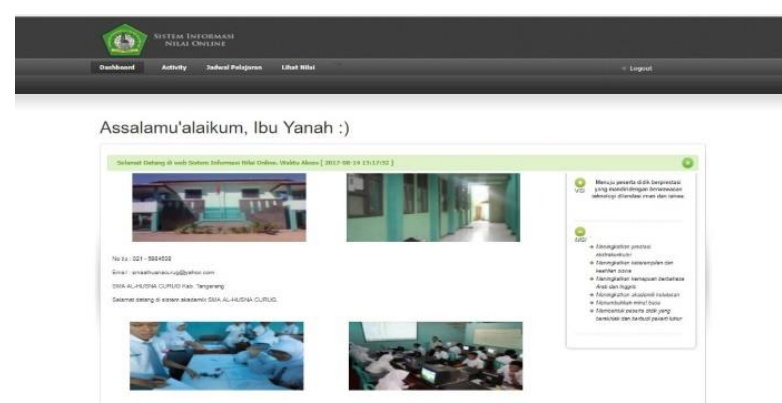

Gambar 11. Tampilan home user 
3. Tampilan Input Nilai

Halaman input nilai sebagai berikut:

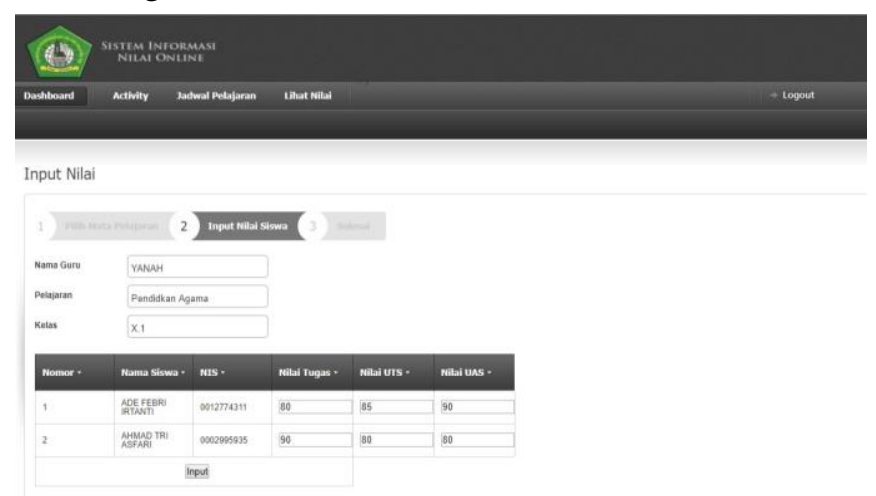

4. Tampilan Input Guru

Gambar 12. Tampilan input nilai

Untuk halaman input guru sebagai berikut:

\section{Data Guru}

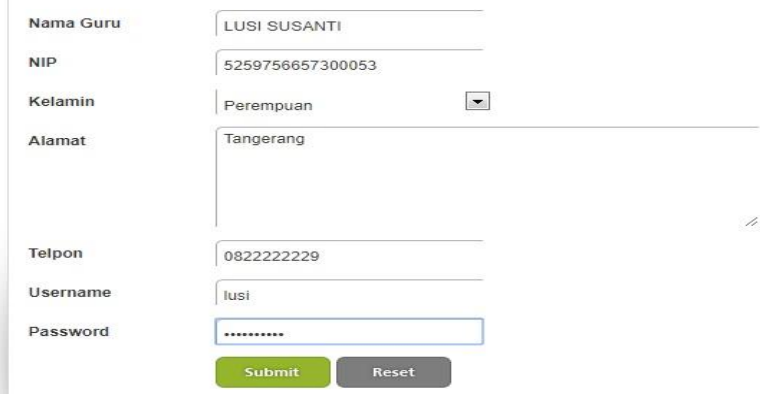

\section{Gambar 13. Halaman input Guru}

5. Tampilan input jadwal pelajaran

Untuk halaman input jadwal pelajaran sebagai berikut:

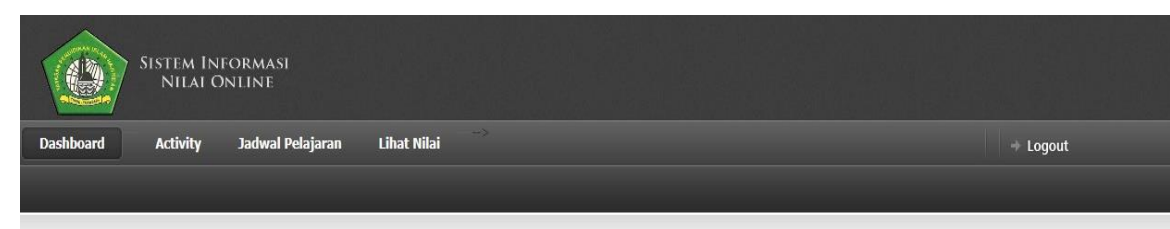

Jadwal Mata Pelajaran

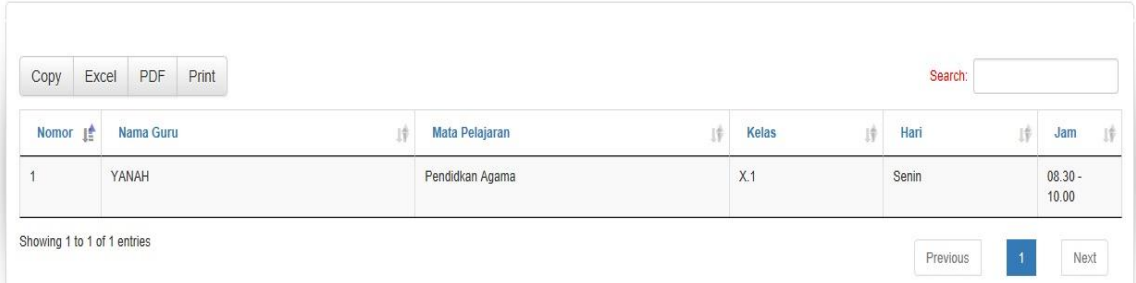

Gambar 14. Tampilan input jadwal pelajaran 
6. Tampilan hasil nilai

Untuk halaman hasil nilai sebagai berikut:

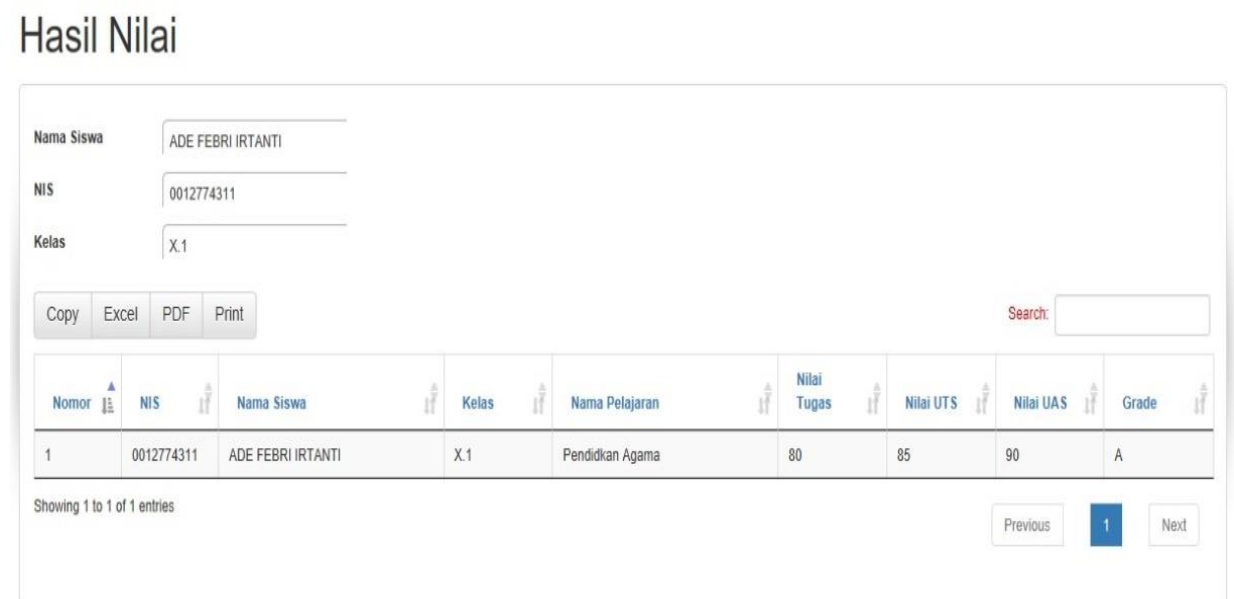

\section{Gambar 15. Tampilan Hasil Nilai}

7. Tampilan Biodata Siswa

Untuk halaman hasil nilai sebagai berikut:

\section{Biodata Siswa}

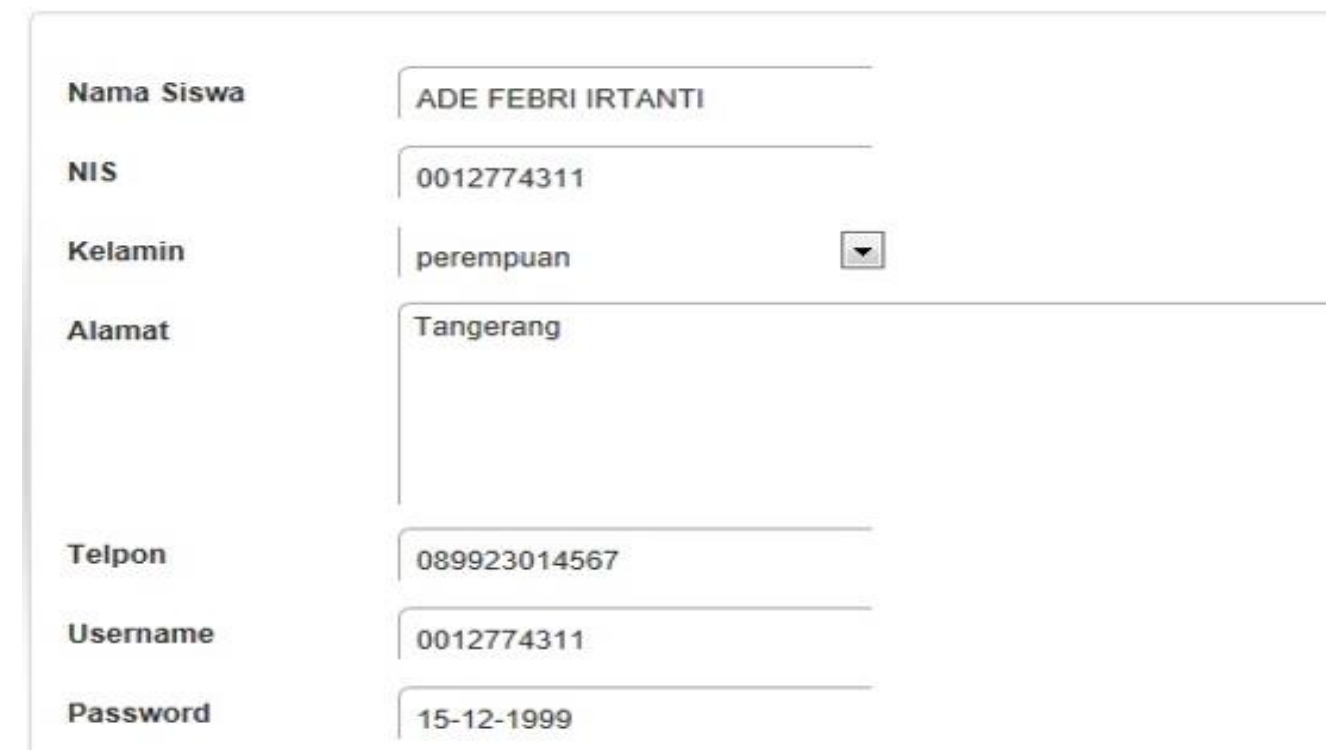

\section{Gambar 16. Tampilan Biodata siswa}

\section{KESIMPULAN}

Berdasarkan hasil penelitian sistem informasi pengolahan data nilai sekolah SMA Al-Husna Curug berbasis web yang telah dilakukan, dapat ditarik kesimpulan antara lain:

1. Pengolahan nilai, penyimpanan laporan lebih efektif karena penyimpanan data dalam database.

2. Dapat membantu dan memudahkan guru dalam mengelola nilai siswa secara cepat dan efesien serta dapat mengetahui jadwal mengajar guru.

3. Dengan adanya ruang halaman siswa dapat mempercepat dan memudahkan siswa dalam menerima informasi siswa seperti jadwal pelajaran dan nilai. 
Sedangkan saran yang diberikan guna lebih mengembangkan pengolahan data nilai SMA AlHusna Curug agar lebih baik yaitu:

1. Perlu adanya maintenance terhadap aplikasi yang sudah dibuat sebelumnya

2. Dapat digunakan backup apabila terjadi error atau kerusakan pada system sehingga keamanan data dapat terjamin

3. Pada penelitian selanjutnya dapat digunakan metode atau modeling yang berbeda sehingga didapatkan kondisi yang maksimal terhadap pengolahan data nilai siswa SMA Al-Husna Curug

\section{DAFTAR PUSTAKA}

[1] Madcoms. Sukses membangun toko online dengan menggunakan PHP \& MySQL. Yogyakarta. Andi 2016:6.

[2] Madcoms. Sukses membangun toko online dengan menggunakan PHP \& MySQL. Yogyakarta. Andi 2016:7.

[3] Madcoms. Teknik Mudah Membangun Website dengan HTML, PHP, dan MySQL Yogyakarta. Andi 2008:52.

[4] Mulhim, Imam. Aplikasi Toko Bangunan Online dengan PHP \& MySQL. Palembang. Maxikom. 2013:2.

[5] Nugroho, Bunafit.Dasar Pemrograman Web PHP-MySQL dengan Dreamweaver. Yogyakarta . Gava Media. 2013:153.

[6] Priyadi, Yudi. Kolaborasi SQL \& ERD dalam Implementasi Database. Yogyakarta. Penerbit Andi. 2014:20.

[7] Raharjo, Budi. Belajar Pemrograman Web Panduan Mudah untuk Pelajar, Mahasiswa, dan Praktisi. Bandung. Penerbit Modula. 2011:221.

[8] S, Rosa A, dan M Salahuddin. Rekayasa Perangkat Lunak Terstruktur \& Berorientasi Objek, Cetakan Kedua. Bandung. Informatika. 2014:133.

[9] Sutabri, Tata. Konsep Sistem Informasi. Yoyakarta. Penerbit Andi. 2012:10.

[10] Sutabri, Tata. Konsep Sistem Informasi. Yoyakarta. Penerbit Andi. 2012:29.

[11] Wayteg, Tom. Kamus Internet. Surabaya: Informatika. 2013:29.

[12] Hakim, Lukmanul. Proyek Website Super Wow! Dengan PHP \& Jquery. Yogyakarta. Penerbit Lokomedia. 2014:3.

[13] Yatiningsih, Fuji. Step by Step Belajar Komputer \& Internet untuk Pemula. Yogyakarta. Buku Pintar. 2013:56.

Lupita Sari, S.Kom, Tahun 2017 lulus dari program strata 1 (S1) Program Studi Sistem Informasi STMIK Nusa Mandiri. 